\title{
Lamellar Body Formation in Normal and Surfactant Protein B-Deficient Fetal Mice
}

\author{
Mildred T. Stahlman, Mary Phillips Gray, Mary W. Falconieri, Jeffrey A. Whitsett, \\ and Timothy E. Weaver
}

Department of Pediatrics (MTS) and Department of Pathology (MPG), Vanderbilt University School of Medicine, Nashville, Tennessee; and Division of Neonatology and Pulmonary Biology (MWF, JAW, TEW), Children's Hospital Medical Center, Cincinnati, Ohio

\begin{abstract}
SUMMARY: Surfactant protein B (SP-B) -/- mice die of lethal respiratory distress syndrome shortly after birth. Alveolar type II epithelial cells in SP-B-deficient mice are characterized by a complete absence of lamellar bodies, the intracellular storage form of pulmonary surfactant, and the presence of inclusions containing numerous small vesicles and electron-dense masses. The present study was undertaken to characterize the formation of these inclusions during fetal lung development and clarify their relationship to lamellar bodies. In wild-type and SP-B +/- mice, small lamellar bodies with loosely organized lamellae and distinct limiting membranes were first detected on day 16 to 16.5 of gestation. SP-B -/- mice were readily identified on day 16 by the absence of immature lamellar bodies, the appearance of vesicular inclusions similar to those previously described in late gestation SP-B -/- mice, and the accumulation of misprocessed SP-C protein. Vesicular inclusions were rarely detected in SP-B $+/-$ mice and were never detected in wild-type littermates. Classical multivesicular bodies were observed fusing with lamellar bodies in wild-type mice, and with the vesicular inclusions in SP-B $-/-$ mice that occasionally contained a few membrane lamellae. On day 18, the airways of SP-B -/- mice lacked tubular myelin and were filled with vesicles and electron-dense masses, suggesting that the contents of the vesicular inclusions were secreted. Taken together, these observations suggest that vesicular inclusions in SP-B -/- mice are disorganized lamellar bodies in which the absence of SP-B leads to failure to package surfactant phospholipids into concentric lamellae. (Lab Invest 2000, 80:395-403).
\end{abstract}

$S$ urfactant is a complex mixture of phospholipids, principally dipalmitoyl phosphatidylcholine and four associated surfactant proteins (SP), designated SP-A, SP-B, SP-C, and SP-D, that lowers intraalveolar surface tension to prevent terminal airway collapse at end expiration. Surfactant is synthesized exclusively by alveolar type II epithelial cells where it is stored in inclusions (lamellar bodies). Lamellar bodies are secreted into the air spaces by exocytosis, where they unravel into a tubular network (tubular myelin) that adsorbs and spreads at the air-liquid interface forming a phospholipid rich film. Surfactant proteins $B$ and $C$ are critical for the rapid adsorption and spreading of this phospholipid film in vitro (Takahashi et al, 1990; Wang et al, 1996; Yu and Possmayer, 1988).

Human SP-B is synthesized by type II epithelial cells as a pre-proprotein of 381 amino acids. The mature peptide is generated by sequential cleavage of the signal peptide (23 amino acids), the $\mathrm{N}$-terminal propeptide (177 residues), and the C-terminal propeptide (102 residues) (O'Reilly et al, 1989; Weaver and Whitsett, 1989). Propeptide cleavage occurs within

Received November 16, 1999.

This research is supported by: HL 38859 (JAW) and HL 56285 (TEW). Address reprint requests to: Dr. M. T. Stahlman, Vanderbilt University Medical Center, Department of Pediatrics, Division of Neonatology, A-0126 Medical Center North, Nashville, Tennessee 37232-2370. Fax: (615) 343-1763; E-mail: mildred.stablman@momail.vanderbilt.edu the late endosomal/multivesicular body compartment that subsequently directs newly synthesized SP-B to the lamellar body for storage or secretion into the airway (Voorhout et al, 1992). Mature SP-B is also recycled from the alveolar space, via the endocytic pathway, to multivesicular bodies for reutilization (Breslin and Weaver, 1992). In 1993, a term infant was first reported to have died from respiratory failure in the postnatal period in association with a lack of SP-B protein and SP-B mRNA in airway secretions or lung tissue. This infant was homozygous for a mutation in the fourth exon of the SP-B gene (Hamvas et al, 1994; Nogee et al, 1993). As in human infants lacking SP-B, SP-B gene-targeted mice die of respiratory failure after birth, associated with lack of normal lamellar bodies and tubular myelin, and the presence of inclusions containing numerous small vesicles and electron-dense masses (Clark et al, 1995). The present study was designed to characterize the formation of these inclusions during fetal lung development and clarify their relationship to lamellar bodies.

\section{Results}

Table 1 shows the strain, gestational age, and genotype of the 45 mice examined by transmission electron microscopy. Fetuses of various gestational ages were examined to assess type II cell morphology before establishment of extracellular surfactant pools and recycling of lipid and protein seen in older animals. 
Table 1. Gestational Age, Genotype Strain, and Number of Transgenic Mice Studied

\begin{tabular}{|c|c|c|c|c|c|}
\hline Gest Age & Genotype & $\begin{array}{l}\mathrm{FVB} / \mathrm{N} \\
(\mathrm{n})\end{array}$ & $\begin{array}{c}\mathrm{FVB} / \mathrm{N} \\
{ }^{*} \mathrm{CS}+1 \\
(\mathrm{n})\end{array}$ & $\begin{array}{c}\mathrm{FVB} / \mathrm{N} \\
{ }^{* *} \mathrm{SD}+1 \\
(\mathrm{n})\end{array}$ & $\begin{array}{c}\text { Swiss Black } \\
\text { (n) }\end{array}$ \\
\hline $15.5 d$ & SP-B-1- & 4 & & & \\
\hline $15.5 d$ & $\mathrm{SP}-\mathrm{B}+1-$ & 5 & & & \\
\hline $15.5 d$ & SP-B $+/+$ & 3 & & & \\
\hline $16.5 d$ & $\mathrm{SP}-\mathrm{B}-1-$ & 1 & & & \\
\hline $16.5 d$ & $S P-B+/-$ & 1 & & & \\
\hline $17-17.5 d$ & SP-B-/- & 2 & & & 2 \\
\hline $17-17.5 d$ & $\mathrm{SP}-\mathrm{B}+1-$ & 2 & & & 2 \\
\hline $17-17.5 d$ & $\mathrm{SP}-\mathrm{B}+1+$ & 4 & & & 2 \\
\hline $18 d$ & SP-B $-1-$ & 2 & & & \\
\hline $18 d$ & SP-B $+1-$ & 2 & & & \\
\hline $18 d$ & SP-B $+/+$ & 1 & & & \\
\hline $18.5 d$ & SP-B-1- & & 1 & 1 & 1 \\
\hline $18.5 d$ & $\mathrm{SP}-\mathrm{B}+1-$ & & 1 & 3 & 1 \\
\hline $18.5 d$ & SP-B +/+ & & 2 & 2 & \\
\hline
\end{tabular}

${ }^{\star}$ C-Section plus 1 minute.

** Spontaneous delivery plus 1 minute.

$n$, number of mice.

In wild-type mice on day 15 to 15.5 of gestation, peripheral airspaces were lined by pre-type II cells with microvilli at the apical surface, the cytoplasm of which contained large pools of monoparticulate glycogen. Monoparticulate glycogen pools were surrounded by rosette glycogen containing abundant dilated rough endoplasmic reticulum, Golgi apparatus, mitochondria, and multivesicular bodies. Multivesicular bodies appeared near Golgi as small dark organelles in which small vesicles were observed, especially visible around the edges of the organelle (Fig. 1). Some multivesicular bodies were larger and not so electron dense. In the pools of monoparticulate glycogen were electron-translucent areas containing strands of lipid membranes, some of which appeared to be surrounding a mass of glycogen. Loosely organized and disorganized lipid whorls that lacked a distinct limiting membrane were common in monoparticulate glycogen pools (Fig. 2). In slightly more mature lungs at 15.5 days gestation, pools of neutral lipid containing multiple concentric lipid membranes were occasionally observed. These characteristics were detected in all three genotypes (SP-B +/+, SP-B +/-, and SP-B -/-) from two distinct strains (FVB/N and Swiss Black). Mature lamellar bodies were never detected at this stage of development and a clear distinction between SP-B -/-, SP-B +/-, and wildtype littermates was not obvious at day 15 to 15.5 of gestation.

In SP-B +/- mice on day 16.5 of gestation, lamellar body lipid membranes were loosely organized into recognizable concentric patterns around dense cores. These immature lamellar bodies were bounded by a limiting membrane and appeared in the rosette glycogen of pre-type II cell cytoplasm, frequently at the edge of the mono-particulate glycogen pool (Fig. 3). Lamellar bodies with dense cores could be found in the alveolar spaces, presumably extruded by exocy- tosis (data not shown). At this stage of development, SP-B -/- mice were readily distinguishable from SP-B +/- littermates. Immature lamellar bodies typical in SP-B +/ - mice were not detected in SP-B -/mice; rather inclusions consisting of many small vesicles and large, irregularly shaped electron-dense masses were detected (Fig. 4). Western blot analyses of lung homogenates clearly detected the misprocessed form of SP-C (Mr = 8k) in SP-B -/- mice, but not wild-type mice (Fig. 5).

At 17.5 days of gestation, lamellar bodies in wildtype mice were readily detected (Fig. 6). The membranes were closely packed, and at high magnification $(\times 80,000)$, the dense cores appeared to be made up of small round, densely packed vesicles with an inner membrane core. Multivesicular bodies were numerous in rosette glycogen pools and their vesicles were usually larger than those of the lamellar body dense cores, but each vesicle had a limiting membrane surrounding a smaller circular core membrane. Some well-developed lamellar bodies were present in the rosette glycogen of pre-type II cells and some were fused with multivesicular body crescents at one pole of the lamellar bodies (Fig. 7). The alveolar spaces contained lipid membranes, mostly in the form of concentric whorls, some containing dense cores and some unraveling to form organized tubular myelin. In addition to typical lamellar bodies observed in wildtype mice, type II cells of SP-B $+/-$ mice rarely contained the vesicular inclusions characteristic of SP-B -/- littermates (Fig. 8A). In type II cells from SP-B -/- mice, this compartment occasionally contained some concentric membrane lamellae, supporting the hypothesis that these structures represent disorganized lamellar bodies (Fig. 8B). Structurally normal multivesicular bodies were detected in type II cells of SP-B -/- mice, some in close approximation to the vesicular inclusions characteristic of SP-B 


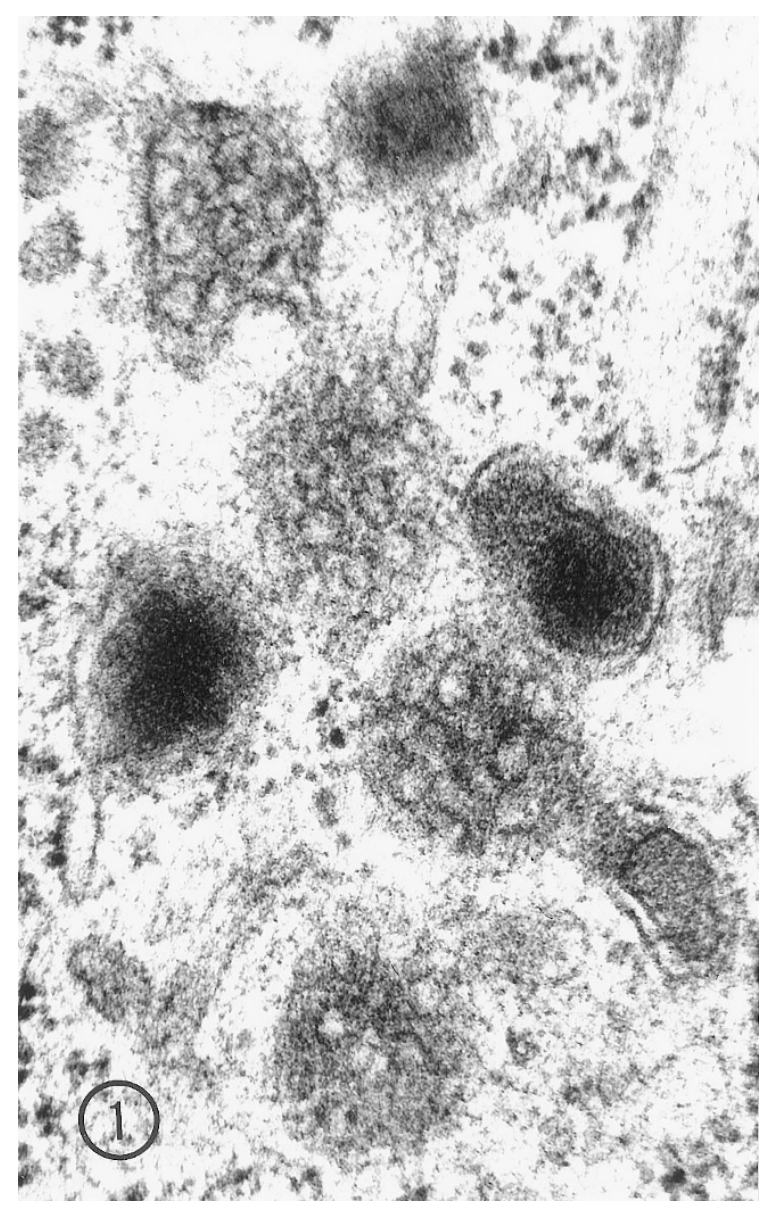

Figure 1

Lung of a 15.5-day gestation FVB/N mouse pup hemizygous for SP-B deficiency. A number of multivesicular bodies in various stages of maturation are seen within rosette glycogen. Some vesicles of these organelles have double limiting membranes that are more visible as they become larger and are more loosely arranged. Uranyl acetate and lead citrate, original magnification, $\times 83,737$

knockout mice (Fig. 9). At this stage of development, fully processed mature SP-B $(\mathrm{Mr}=18 \mathrm{k})$ and SP-C (Mr-4k) were detectable in wild-type mice, but not SP-B $-/-$ mice (Fig. 5).

The most characteristic feature in the lungs of wild-type mice delivered by Cesarean section on day 18.5 of gestation was the accumulation of surfactant in the airway (Fig. 10). Concentric whorls of membrane and lamellar bodies were unraveling and forming tubular myelin in wild-type SP-B +/+ and SP-B +/mice. Occasionally, lamellar bodies with a thin rim of cytoplasm were detected in the air space, consistent with apocrine secretion (Fig. 10). The airways of SP-B $-/-$ mice lacked tubular myelin and were filled with vesicles and electron-dense masses similar to those detected in the vesicular inclusions in type II cells (Fig. 11). This finding suggests that the contents of these organelles can be secreted, and further supports the hypothesis that these structures are disorganized lamellar bodies. Similar to type II cells on day 17 to 7.5 of gestation, normal multivesicular bodies and multivesicular bodies fusing with the vesicular inclusions

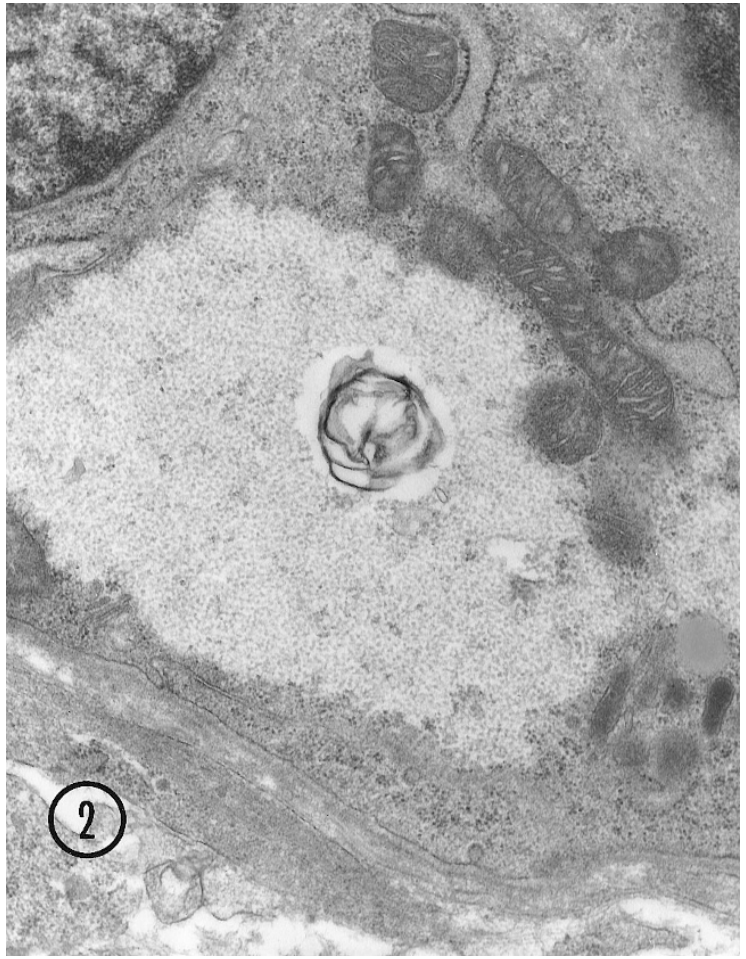

Figure 2.

Lung of a 15.5-day gestation FVB/N mouse pup hemizygous for SP-B deficiency, showing concentric rings of lipid membrane organizing within a pool of monoparticulate glycogen in a type II cell. Multivesicular bodies in various stages of development can be seen at the lower right near a lipid droplet. The rough endoplasmic reticulum is dilated. Uranyl acetate and lead citrate, original magnification, $\times 35,875$

were detected in SP-B -/- mice (Fig. 12). Findings in mice delivered spontaneously and allowed to breathe for one minute were essentially identical to the corresponding genotype on day 18.5 of gestation. No differences were detected between Swiss Black and FVB/N mice on days 16 to 18 of gestation.

\section{Discussion}

The autoradiographic studies of Chevalier and Collet suggested that newly synthesized protein was shuttled to the lamellar body via multivesicular bodies (Chevalier and Collet, 1972). Consistent with this hypothesis, processing of the SP-B and SP-C proproteins to their mature peptides was shown to occur in the multivesicular body (Voorhout et al, 1992; Vorbroker et al, 1995a; 1995b), and Henry et al (1996) reported that newly synthesized mature SP-B peptide accumulated in lamellar bodies before its appearance in alveolar wash. The present study clearly demonstrated that multivesicular bodies fuse with lamellar bodies at a point in gestation when the surfactant recycling pathway is likely inactive, suggesting that these organelles are part of the biosynthetic pathway. Collectively the results of these studies support the hypothesis that the multivesicular body plays a critical role in the biogenesis of lamellar bodies during lung development. 


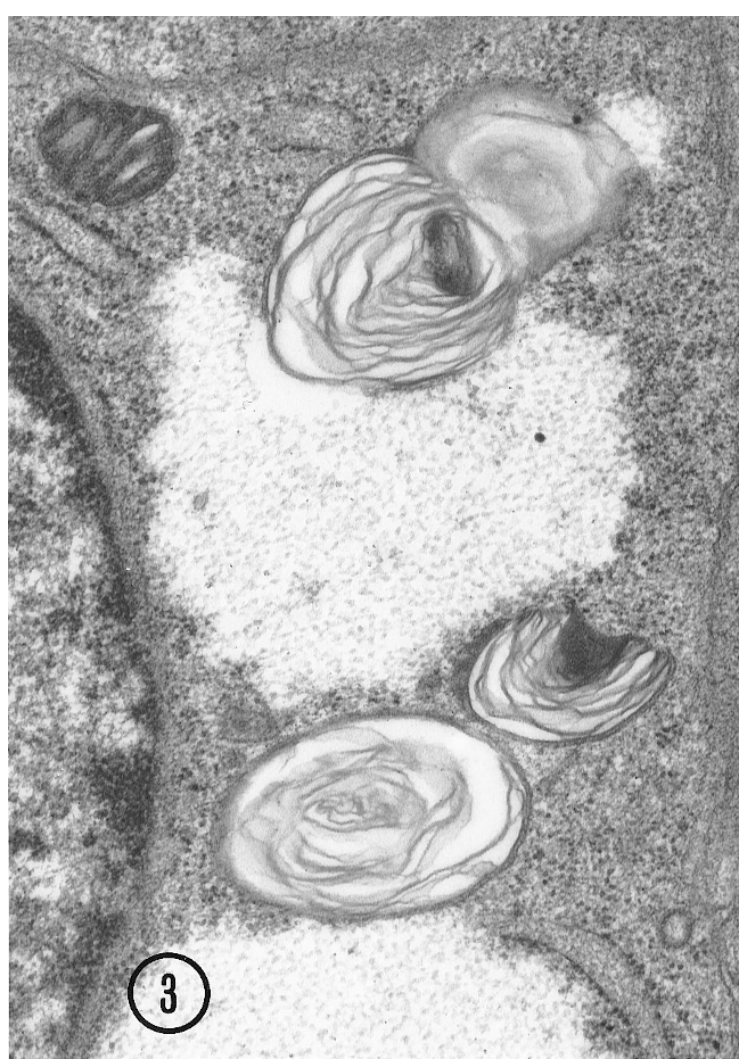

\section{Figure 3.}

Lung of a 16.5-day gestation FVB/N mouse pup hemizygous for SP-B deficiency. Putative lamellar bodies, two with dense cores, lie in rosette glycogen on the edge of monoparticulate glycogen pools. Uranyl acetate and lead citrate, original magnification, $\times 41,000$.

The formation of the multivesicular bodies in SP-B -/- mice was not different from wild-type littermates throughout gestation. Multivesicular bodies were detected on day 15 of gestation before detection of SP-B protein or formation of lamellar bodies. Disorganized or loosely organized strands of lipids resembling immature lamellar bodies were detected in monoparticulate glycogen pools; however, these structures lacked a clear limiting membrane and there was no striking difference between wild-type or SP-B +/- and SP-B $-/-$ mice. It therefore remains unclear if these lipids contribute to lamellar body formation in the developing lung.

Coincident with the first detection of immature lamellar bodies (day 16 to 16.5 of gestation), inclusions containing small vesicles and irregularly shaped electron-dense masses were detected in SP-B -/mice. The latter organelles occasionally contained a few lamellae and fusion with multivesicular bodies was frequently observed. The contents of these inclusions detected in the airway were consistent with secretion. Collectively, these observations suggest that these organelles are disorganized lamellar bodies in which the absence of SP-B leads to failure to package surfactant phospholipids into concentric lamellae.

Only the mature SP-B peptide is detected in lamellar bodies of type II cells in adult mice (Voorhout et al, 1992; Weaver and Whitsett, 1989), suggesting that

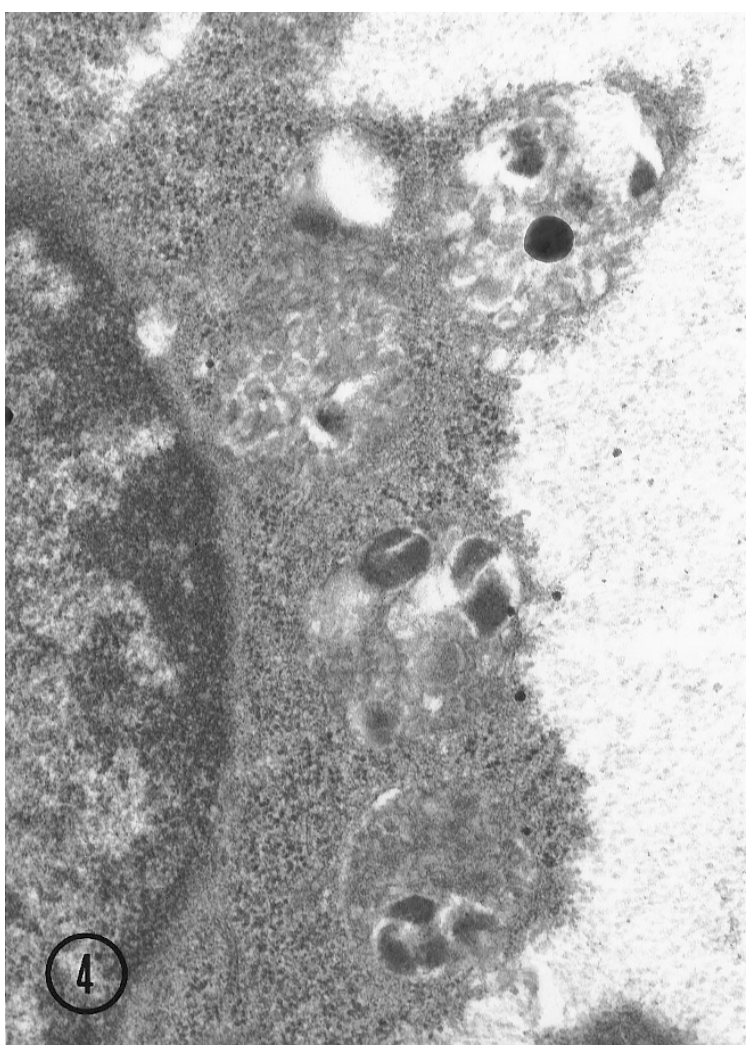

Figure 4.

Lung of a 16.5-day gestation FVB/N mouse pup homozygous for SP-B deficiency. Multiple vesicular inclusions are present in rosette glycogen. These are made up of collections of dense, irregular shaped masses and many electron-translucent small vesicles. Uranyl acetate and lead citrate, original magnification, $\times 32,042$.

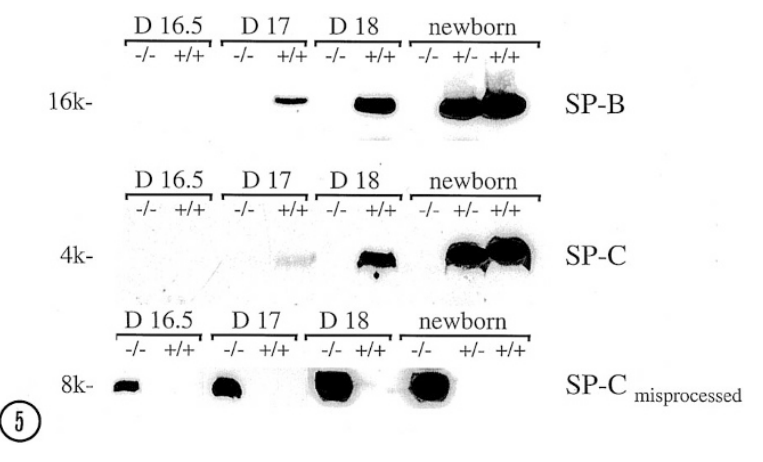

\section{Figure 5.}

SP-B $+1-$ mice were crossed and lung tissues collected from newborn mice or from fetuses on day 18,17, or 16.5 of gestation. Equal amounts of protein from each developmental stage were analyzed by SDS-PAGE/Western blotting to detect the mature SP-B peptide $(\mathrm{Mr}=16 \mathrm{k})$, the mature SP-C peptide $(\mathrm{Mr}=$ $4 \mathrm{k})$, and the misprocessed form of SP-C $(\mathrm{Mr}=8 \mathrm{k})$.

this form of SP-B is critical for organization of surfactant lipids into concentric lamellae. Mature SP-B peptide was first detected in wild-type mice on day 17 of gestation; however, given the appearance of normally organized lamellar bodies on day 16.5 of gestation, it seems likely that processing of the SP-B proprotein also occurs at this stage of development and that failure to detect the mature peptide by Western blotting reflects levels of SP-B below the limits of detec- 


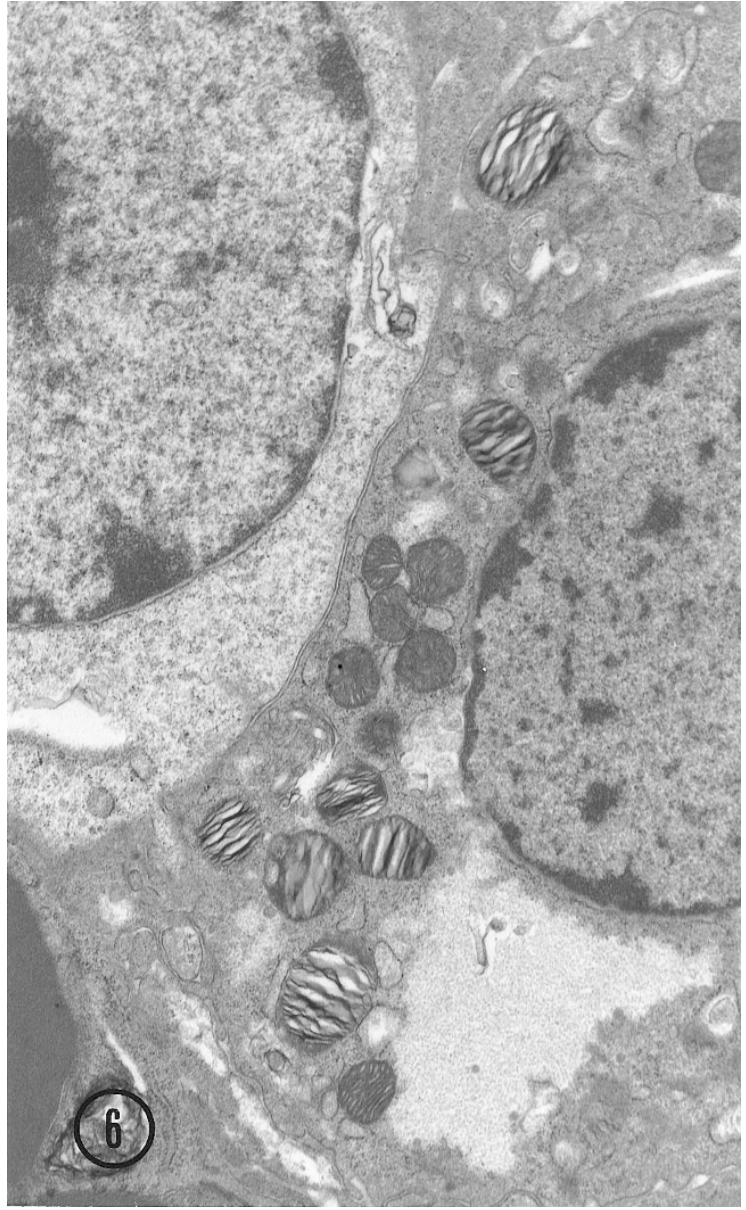

\section{Figure 6 .}

Type II cell from a 17-day gestation wild-type FVB/N mouse pup showing a number of well-developed, mature appearing lamellar bodies interspersed with mitochondria in rosette glycogen. Uranyl acetate and lead citrate, original magnification, $\times 12,843$.

tion. Similar to SP-B, mature SP-C peptide was first detected on day 17 of gestation; however, the misprocessed form of SP-C was readily detected in SP-B $-/-$ mice on day 16.5 , coincident with the first appearance of disorganized lamellar bodies. These results indicate that the earliest markers of the SP-B -/- genotype are the accumulation of misprocessed SP-C and the appearance of disorganized lamellar bodies.

Disorganized lamellar bodies were never detected in wild-type mice but were occasionally observed in SP-B +/- fetal mice on or after day 17 to 17.5 of gestation. Failure to observe disorganized lamellar bodies on day 16 to 16.5 of gestation is likely related to the small number of lamellar bodies at this developmental stage. The occurrence of disorganized lamellar bodies in SP-B $+/-$ mice suggests that SP-B may be limiting in SP-B $+/-$ mice during fetal lung development. Consistent with this conclusion, levels of mature SP-B peptide increased dramatically between 17 and 18 days of gestation. These findings suggest that SP-B +/- fetuses may be at a significant disadvantage if prematurely delivered during this gestational window. Heterozygote susceptibility has pre-

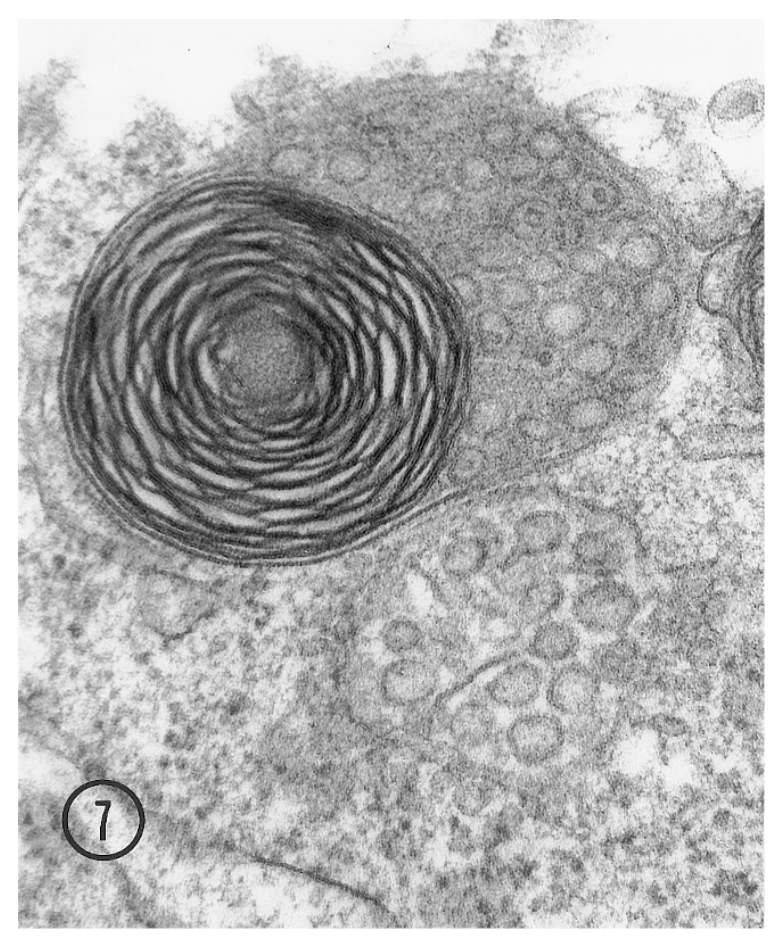

Figure 7.

Lung of a 17.5-day gestation Swiss Black mouse pup hemizygous for SP-B deficiency showing a well-developed lamellar body with a dense core fusing with a crescent-shaped multivesicular body (MVB), apparently being incorporated within its limiting membrane. Some of the vesicles show an inner membrane core. A second MVB is nearby. Uranyl acetate and lead citrate, original magnification, $\times 71,775$.

viously been reported for SP-B +/- adult mice that had decreased lung compliance and abnormalities of inflation/deflation curves consistent with airway collapse at low deflation pressures (Clark et al, 1997). Decreased pulmonary function and increased alveolar-capillary leak were also observed in SP-B $+/-$ mice after exposure to 95\% oxygen (Tokieda et al, 1999).

In summary, SP-B deficiency leads to the formation of disorganized lamellar bodies that are first detected on day 16 to 16.5 of gestation. The contents of these lamellar bodies are secreted into the airspace but fail to form a functional surfactant film, leading to lethal respiratory distress syndrome shortly after birth.

\section{Materials and Methods}

Targeted embryonic stem cells carrying the disrupted SP-B allele were generated in the 129J strain (Clark et al, 1995). Chimeric mice (carrying one disrupted SP-B allele) were bred with Swiss Black mice, an out-bred strain. The SP-B knockout colony was maintained by breeding hemizygous males to wild-type Swiss Black females. To ensure a uniform genetic background, hemizygous males were crossed to wild-type FVB/N females, an inbred strain, for a total of nine generations.

Timed pregnant mice from both colonies were delivered by Cesarean section under sodium pentobarbital anesthesia, and with the exception of the 18.5- 

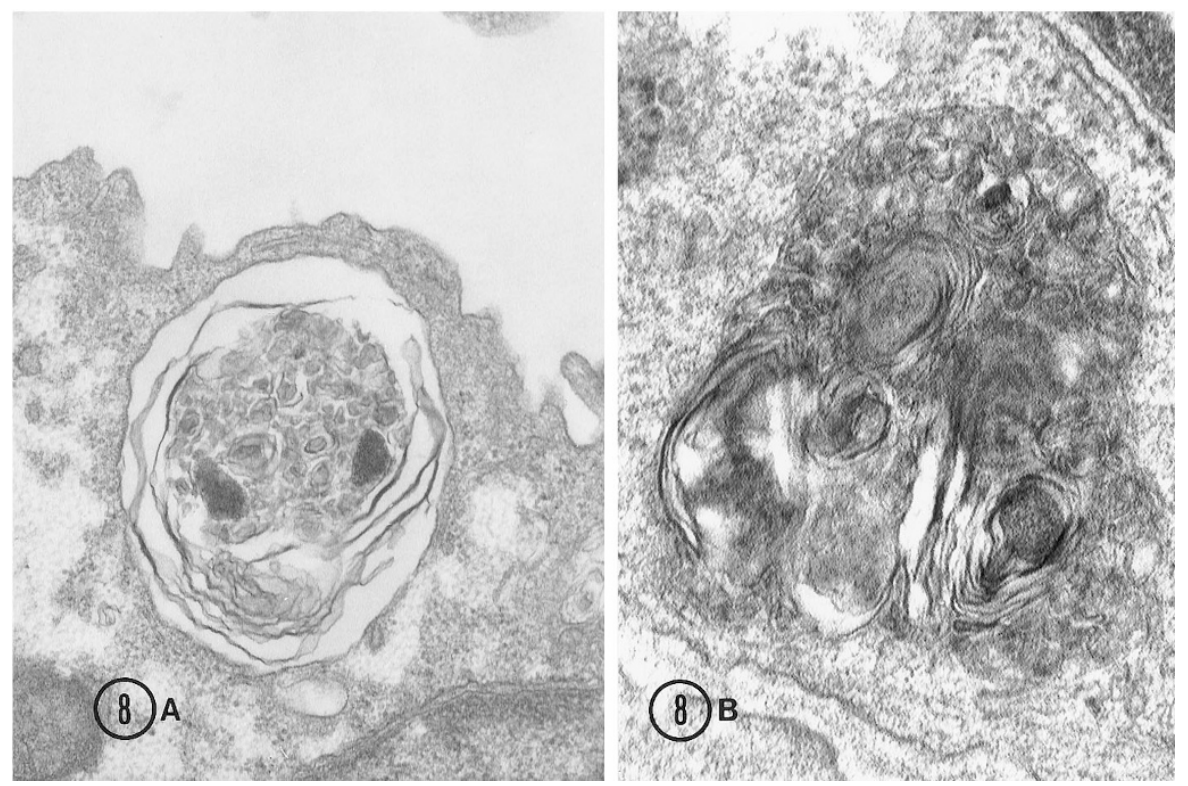

Figure 8 .

A, Lung of an 18-day gestation FVB/N mouse pup hemizygous for SP-B deficiency showing an organelle consisting of strands of lipid surrounding multiple disorganized vesicles and several electron-dense structures. Uranyl acetate and lead citrate, original magnification, $\times 33,756$. B, Lung of a 17-day gestation homozygous Swiss Black mouse pup showing an abnormal collection of putative lamellar bodies, some with dense cores. These are fusing with what appears to be an abnormal multivesicular body at the upper pole and on both lower sides. Uranyl acetate and lead citrate, original magnification, $\times 67,785$.

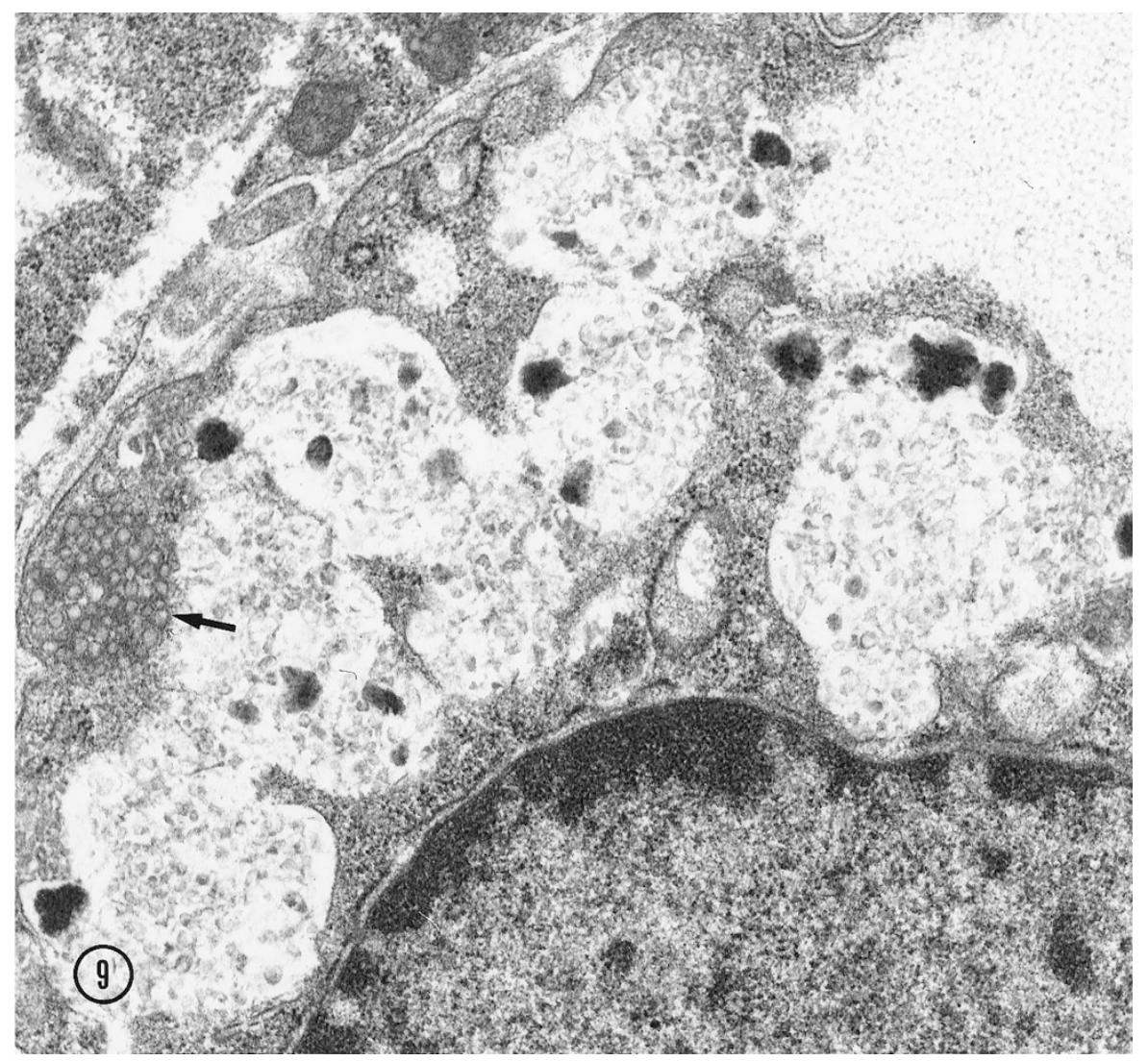

\section{Figure 9.}

Type II cell of a 17.5-day gestation FVB/N mouse pup homozygous for SP-B deficiency showing many vesicular inclusions. These are multi-compartmentalized structures filled with many electron translucent vesicles and electron-dense irregularly shaped particles of condensed lipid. A normal multivesicular body can be seen near one of these structures (arrow). Uranyl acetate and lead citrate, original magnification, $\times 71,775$. 


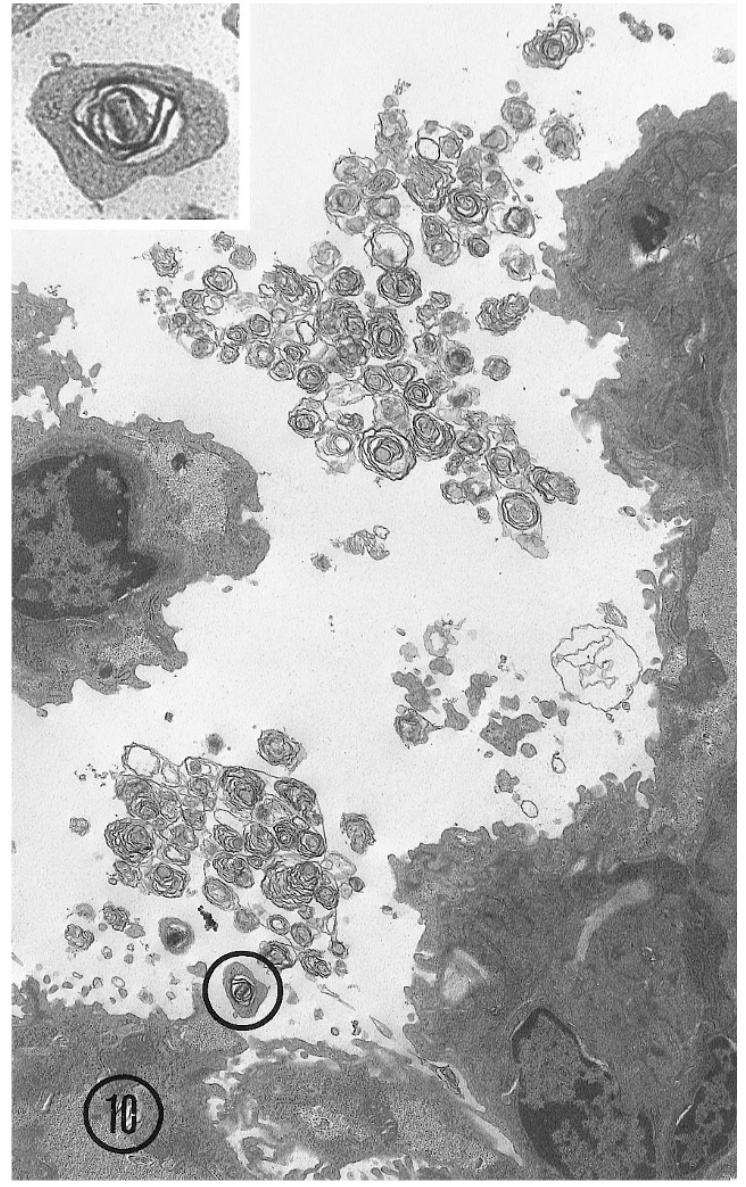

Figure 10.

Lung of an 18.5-day gestation wild-type FVB/N mouse pup delivered by Cesarean section and allowed to breath one minute. Airway debris consists of many concentric lipid whorls, a few containing dense cores. Two lamellar bodies surrounded by rims of cytoplasm are detected in the airway, suggesting exocrine secretion. Uranyl acetate and lead citrate, original magnification, $\times 6,400$. Insert shows one of these lamellar bodies. Uranyl acetate and lead citrate, original magnification, $\times 20,000$.

day animals, killed by decapitation at birth. One 18.5day FVB/N litter was delivered by Cesarean section and each pup was allowed to breathe for one minute before being killed. A second 18.5-day FVB/N litter was allowed to spontaneously deliver and each newborn was allowed to breathe for one minute before decapitation.

For electron microscopy, lung tissue from the left lobe was minced into $1-\mathrm{mm}^{3}$ pieces, immersed in modified Karnovsky's solution (2\% paraformaldehyde, $2 \%$ gluteraldelyde, $0.1 \mathrm{M}$ sodium cacodylate buffer [SCB], at $\mathrm{pH}$ 7.3), fixed overnight in modified Karnovsky's solution at $4^{\circ} \mathrm{C}$, rinsed $4 \times 15$ minutes each in $0.1 \mathrm{M} \mathrm{SCB}$, and stored in $7.5 \%$ sucrose in $0.1 \mathrm{M}$ SCS for shipment. Tissues were post-fixed in MilIonig's osmium tetroxide (Millonig, 1961) for 2 hours, dehydrated by Luft's procedure (Luft, 1961) and embedded in Spurr (EM Sciences, Fort Washington, Pennsylvania). Semi-thin sections, stained with toluidine blue, were examined by light microscopy and fields selected for thin sectioning. Thin sections were cut with a diamond knife, mounted on uncoated

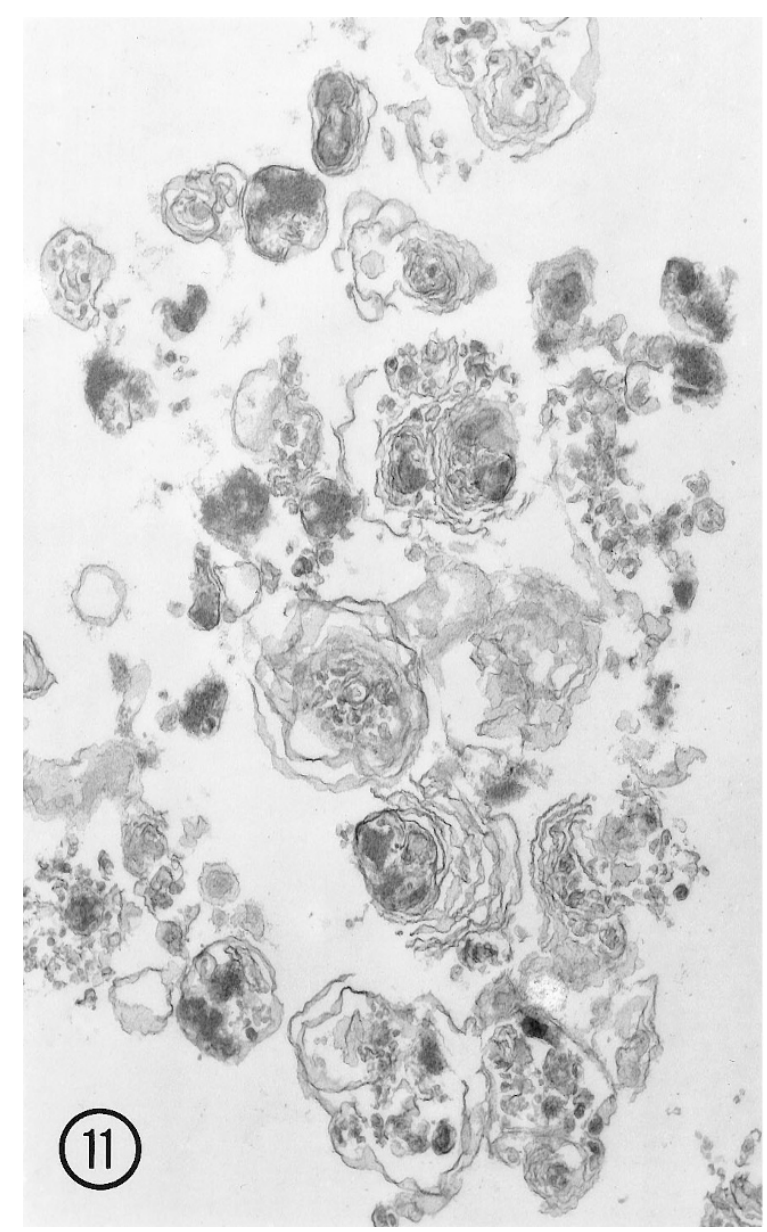

Figure 11

Airway debris of an 18.5-day gestation FVB/N mouse pup homozygous for SP-B deficiency delivered by Cesarean section and allowed to breathe for one minute. Abundant airway debris consists of many vesicular inclusions both whole and disintegrating and much amorphous debris. Uranyl acetate and lead citrate, original magnification, $\times 18,041$.

copper mesh grids, doubly stained with uranyl acetate and lead citrate, and observed on a Phillips 300 electron microscope.

For Western blot analyses, $50 \mu \mathrm{g}$ of protein from total lung homogenates isolated from fetuses on day 16,17 , and 18 of gestation, and newborn mice were subjected to SDS-PAGE and transferred to nitrocellulose. Western blotting was performed as previously described (Lin et al, 1999) with antiserum 28031 (Lin et al, 1996) directed against the mature SP-B peptide, antiserum 68514 (Vorbroker et al, 1995a; 1995b) directed against the SP-C proprotein, or antiserum 2296 (Ross et al, in press) directed against recombinant human mature SP-C peptide.

\section{Acknowledgements}

We wish to thank Ms Deborah Brown and Mr. Elvin Woodruff III for technical help with the electron microscopic section preparation and printing, Mrs. Anita Taylor and Ms Ann Maher for manuscript preparation, and Ms Jean Clark for generation of the SP-B -/mice. 


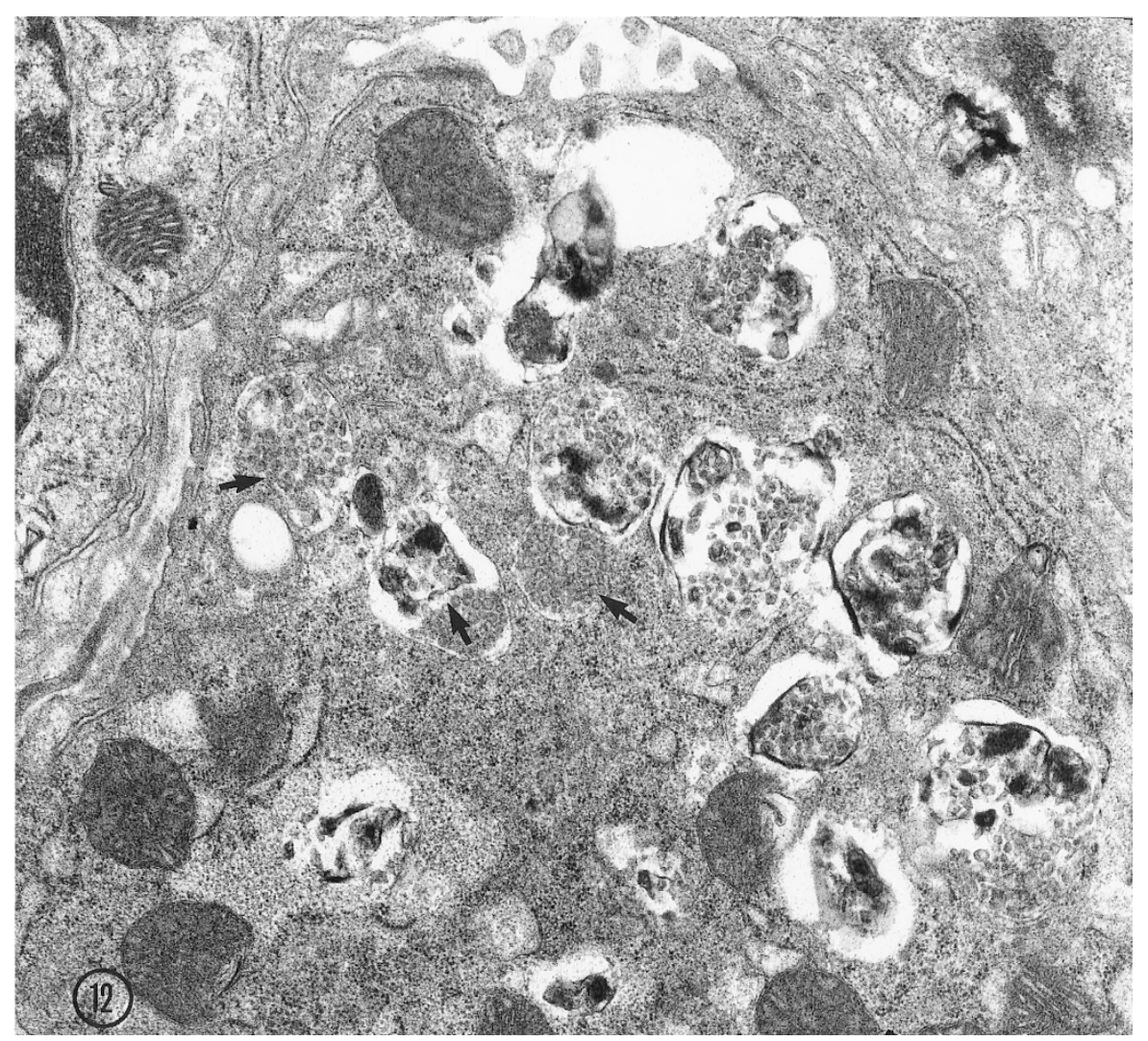

Figure 12.

Lung of a newborn Swiss Black mouse pup homozygous for SP-B deficiency showing multiple vesicular inclusions containing multiple disorganized vesicles and electron-dense particles. Normal multivesicular bodies are present (arrows). Uranyl acetate and lead citrate, original magnification, $\times 10,125$.

\section{References}

Breslin JS and Weaver TE (1992). Binding, uptake, and localization of surfactant protein $B$ in isolated rat alveolar type II cells. Am J Physiol 262(6 Pt 1):L699-L707.

Chevalier G and Collet AJ (1972). In vivo incorporation of choline- $3 \mathrm{H}$, leucine- $3 \mathrm{H}$ and galactose- $3 \mathrm{H}$ in alveolar type II pneumocytes in relation to surfactant synthesis: A quantitative radioautographic study in mouse by electron microscopy. Anat Rec 174(3):289-310.

Clark JC, Weaver TE, Iwamoto HS, Ikegami M, Jobe AH, Hull WM, and Whitsett JA (1997). Decreased lung compliance and air trapping in heterozygous SP-B-deficient mice. Am J Respir Cell Mol Biol 16:46-52.

Clark JC, Wert SE, Bachurski CJ, Stahlman MT, Stripp BR, Weaver TE, and Whitsett JA (1995). Targeted disruption of the surfactant protein B gene disrupts surfactant homeostasis, causing respiratory failure in newborn mice. Proc Natl Acad Sci USA 92(17):7794-7798.

Hamvas A, Cole FS, deMello DE, Moxley M, Whitsett JA, Colten HR, and Nogee LM (1994). Surfactant protein B deficiency: Antenatal diagnosis and prospective treatment with surfactant replacement. J Pediatr 125(3):356-361.

Henry M, Ikegami M, Ueda T, and Jobe A (1996). Surfactant protein $\mathrm{B}$ metabolism in newborn rabbits. Biochim Biophys Acta 1300(2):97-102.

Lin S, Na CL, Akinbi HT, Apsley KS, Whitsett JA, and Weaver TE (1999). Surfactant protein B (SP-B) $-/-$ mice are rescued by restoration of SP-B expression in alveolar type II cells but not Clara cells. J Biol Chem 274(27):19168-19174.

Lin S, Phillips KS, Wilder MR, and Weaver TE (1996). Structural requirements for intracellular transport of pulmonary surfactant protein B (SP-B). Biochim Biophys Acta 1312(3): 177-185.

Luft JH (1961). Improvements in epoxy resin embedding methods. J Biophys Biochem Cytol 9:409-414.

Millonig G (1961). Advantages of a phosphate buffer for OsO4 solutions in fixation. J Appl Physics 32:1637.

Nogee LM, DeMello DE, Dehner LP, and Colten HR (1993). Brief report: Deficiency of pulmonary surfactant protein $B$ in congenital alveolar proteinosis. N Engl J Med 328(6):406410.

O'Reilly MA, Weaver TE, Pilot-Matias TJ, Sarin VK, Gazdar AF, and Whitsett JA (1989). In vitro translation, posttranslational processing and secretion of pulmonary surfactant protein B precursors. Biochim Biophys Acta 1011:140 148.

Ross GF, Ikegami M, Steinhilber W, and Jobe AH (1999). Surfactant protein $\mathrm{C}$ in fetal and ventilated preterm rabbit lungs. Am J Physiol 277:L1104-L1108.

Takahashi A, Waring AJ, Amirkhanian J, Fan B, and Taeusch HW (1990). Structure-function relationships of bovine pulmonary surfactant proteins: SP-B and SP-C. Biochim Biophys Acta 1044:43-49. 
Tokieda K, Iwamoto HS, Bachurski C, Wert SE, Hull WM, Ikeda K, and Whitsett JA (1999). Surfactant protein-B deficient mice are susceptible to hyperoxic lung injury. Am $\mathrm{J}$ Respir Cell Mol Biol 21:463-472.

Voorhout WF, Veenendaal T, Haagsman HP, Weaver TE, Whitsett JA, van Golde LM, and Geuze HJ (1992). Intracellular processing of pulmonary surfactant protein $B$ in an endosomal/lysosomal compartment. Am J Physiol 263(4 Pt 1):L479-L486.

Vorbroker DK, Profitt SA, Nogee LM, and Whitsett JA (1995a). Aberrant processing of surfactant protein C (SP-C) in hereditary SP-B deficiency. Am J Physiol: Lung Cell Mol Physiol 268(4 Pt 1):L647-L656.

Vorbroker DK, Voorhout WF, Weaver TE, and Whitsett JA (1995b). Posttranslational processing of surfactant protein $C$ in rat type II cells. Am J Physiol 269(6 Pt 1):L727-L733.
Wang Z, Hall SB, and Notter RH (1996). Roles of different hydrophobic constituents in the adsorption of pulmonary surfactant. J Lipid Res 37(4):790-798.

Weaver TE and Whitsett JA (1989). Processing of hydrophobic pulmonary surfactant protein $B$ in rat type II cells. Am $J$ Physiol 257(2 Pt 1):L100-L108.

Yu SH and Possmayer F (1988). Comparative studies on the biophysical activities of the low-molecular-weight hydrophobic proteins purified from bovine pulmonary surfactant. Biochim Biophys Acta 961(3):337-350. 